\title{
An Overview on the Potential Roles of EGCG in the Treatment of COVID-19 Infection
}

\author{
Sabrina Bimonte $\mathbb{D}^{1, *}$ \\ Cira Antonietta Forte (D) ${ }^{1, *}$ \\ Massimiliano Cuomo ${ }^{2}$ \\ Gennaro Esposito (D) \\ Marco Cascella iD ${ }^{\prime}$ \\ Arturo Cuomo (iD) \\ 'Division of Anesthesia and Pain \\ Medicine, Istituto Nazionale Tumori - \\ IRCCS - Fondazione G. Pascale, Naples, \\ Italy; ${ }^{2}$ S.C. Project Management \\ e Formazione, Istituto Nazionale Tumori \\ - IRCCS - Fondazione G. Pascale, Naples, \\ Italy
}

*These authors contributed equally to this work
Correspondence: Sabrina Bimonte Division of Anesthesia and Pain Medicine, Istituto Nazionale dei Tumori, IRCCS Fondazione G. Pascale, Naples, Italy Email s.bimonte@istitutotumori.na.it

\begin{abstract}
Coronavirus disease-19 (COVID-19) pandemic is currently ongoing worldwide and causes a lot of deaths in many countries. Although different vaccines for the severe acute respiratory syndrome coronavirus-2 (SARS-CoV-2) infection have been developed and are now available, there are no effective antiviral drugs to treat the disease, except for Remdesivir authorized by the US FDA to counteract the emergency. Thus, it can be useful to find alternative therapies based on the employment of natural compounds, with antiviral features, to circumvent SARS-CoV-2 infection. Pre-clinical studies highlighted the antiviral activities of epigallocatechin-3-gallate (EGCG), a catechin primarily found in green tea, against various viruses, including SARS-CoV-2. In this review, we summarize this experimental evidence and highlight the potential use of EGCG as an alternative therapeutic choice for the treatment of SARS-CoV-2 infection.
\end{abstract}

Keywords: COVID-19, EGCG, SARS-CoV-2, tea polyphenols, antiviral properties

\section{Introduction}

SARS-Cov-2 is a novel coronavirus causing the severe acute respiratory syndrome spreading around the world since the end of 2019. ${ }^{1,2}$ It belongs to a family of singlestranded RNA viruses (+ssRNA), as the severe acute respiratory syndrome virus (SARS-CoV) and the Middle East respiratory syndrome virus (MERS-CoV). SARSCoV-2 infection can cause mild to severe pneumonia and its mortality rate is higher in patients with comorbidities and older patients. ${ }^{3,4}$ Although different vaccines for the severe acute respiratory syndrome coronavirus-2 (SARS-CoV-2) infection have been developed and are now available, ${ }^{5}$ there are no effective antiviral drugs to treat the disease, except for Remdesivir authorized by the United States Food and Drug Administration (US FDA) to counteract the emergency. ${ }^{6}$ mRNA-based vaccines were developed by Moderna and Pfizer/BioNTech, ${ }^{7,8}$ but there is still uncertainty about their efficacy ( 95\%), safety, and immunogenicity concerning SARS-CoV-2 spike glycoprotein (S protein). Similarly, viral vector vaccines were produced by Johnson and Johnson and by the University of Oxford/AstraZeneca, although the safety of AstraZeneca's vaccine is currently under revision. ${ }^{9,10}$ Unfortunately, new strains of the virus have developed so far with new mutations and this could inhibit the effectiveness of vaccines, and delays the end of the pandemic. ${ }^{11}$ Given the high infectivity of new mutations in the virus and the slowness of vaccine programming, herd immunity will be difficult to achieve in a short time. It is very likely that new coronavirus diseases may still emerge in the future. Thus, it can be necessary to develop alternative therapies based on the use of natural compounds, as 
epigallocatechin-3-gallate (EGCG), with antiviral features, to circumvent SARS-CoV-2 infection. EGCG, is the principal constituent and most important polyphenolic catechin found in green tea. ${ }^{12-18}$ As largely reported, EGCG possesses many biological properties (ie antioxidant, antitumor, anti-inflammatory) due to a galloyl side chain contained in its chemical structure. ${ }^{19}$ It has been shown that polyphenols and EGCG, through sticking with some molecules present in viruses, are able to regulate their functions. Specifically, EGCG by binding to the receptors present on the membrane of the host cells or directly to the viral surface inhibits the interaction between the host cells and the virus. As a result, EGCG represses the replication and the transcription of the virus, thus inactivating its activity. $^{20,21}$ As recently detailed described by Wang et al, ${ }^{22}$ EGCG has inhibitory activities towards different viruses. Specifically, EGCG is able to suppress the replication, the transcription and the infection of DNA virus as Hepatitis B Virus (HBV), ${ }^{23-27}$ Herpes Simplex Virus $(\mathrm{HSV})^{28-31}$ and Epstein-Barr Virus (EBV) through different molecular mechanisms. ${ }^{32-35}$ Moreover, EGCG has similar effects on RNA virus as Human Immunodeficiency Virus (HIV), ${ }^{37-42}$ Hepatitis C virus (HCV), ${ }^{43-45}$ and Influenza A virus (IAV) ${ }^{46-48}$ Additionally, in vitro studies demonstrated that EGCG is capable to inhibit the replication of some Enterovirus (CVB3, EV71) by regulating the oxidative stress of host cells. ${ }^{49,50}$ Similar effects were also detected in Arboviruses, particularly in Chikungunya virus (CHIKV). ${ }^{51-55}$ Finally, several pre-clinical studies confirmed the antiviral activity of EGCG also against Coronaviruses, especially against SARS-Cov- $2 .{ }^{56-73}$ Basically, EGCG can inhibit the cell entry of these viruses or their replication and transcription, through different molecular mechanisms which are not completely known. In this review, we summarize these experimental pieces of evidence and highlighted the potential use of EGCG as an alternative therapeutic choice for alleviating or treat SARSCov-2 infection.

\section{The Antiviral Activity of EGCG Against SARS-Cov-2: Findings from Preclinical Studies}

COVID-19 is caused by SARS-CoV-2 infection. ${ }^{56}$ The initial clinical manifestations of COVID-19 include respiratory symptoms, such as fever, fatigue and dry cough, are accompanied by atypical clinical manifestations such as sore throat, headache and diarrhea. ${ }^{57}$ Around one week later, patients exhibited difficulty breathing and hypoxia, during which the secretion of intracellular pro-inflammatory factors Interleukin-6 (IL-6), Interleukin-17 (IL-17) and tumor necrosis factor $\alpha(\mathrm{TNF}-\alpha)$ ) increased significantly, and the total number of circulating lymphocytes decreased. Then, the symptoms rapidly deteriorated into acute respiratory distress syndrome (ARDS), sepsis, blood coagulation dysfunction and irreversible metabolic acidosis. Eventually, some severe cases would lead to death. Structurally, SARS-CoV-2 contains four proteins including spike (S), envelope (E), membrane (M), and nucleocapsid (N) proteins. During host cell entry, SARS-CoV -2 relies on its $\mathrm{S}$ proteins for binding to the host cell-surface receptor. The $\mathrm{S}$ protein binds to the host receptor through the receptor-binding domain (RBD) in the $\mathrm{S} 1$ subunit, followed by the fusion of the $\mathrm{S} 2$ subunit to the cell membrane. SARS$\mathrm{CoV}-2$ recognizes the cell membrane receptor angiotensinconverting enzyme 2 (ACE2) receptor to bind with the viral $\mathrm{S}$ protein, thus forming RBD-ACE2 complex, by which the virus is embedded into the host cell where it starts replication. Thus, if a substance can bind the $\mathrm{S}$ protein, or possesses a strong affinity to $\mathrm{ACE} 2$ receptor, which blocks the formation of RBD-ACE2 complex, it could suppress the viral entry into host cells. Regarding the antiviral effects of EGCG on SARSCoV-2, different pre-clinical studies have been performed (Table 1). Basically, the inhibition effects of EGCG on SARSCoV-2 replication occur through its actions on the ACE2 receptor, the main protease (Mpro, a 3C-like protease) and RNA-dependent RNA polymerase (RdRp) (Figure 1).

Mhatre et $\mathrm{al}^{58}$ reviewed the antiviral activities of EGCG theaflavin-3,3'-digallate (TF3) against positive-sense single-stranded RNA viruses, including SARS-CoV-2. The authors suggested that both the tea polyphenols are capable to interact with the receptors present in the structure of SARS-CoV-2 virus, thus inhibiting its replication. Particularly, the theaflavins (TFs), can be employed as prophylactic agents due to their capacity to bind Spike receptor-binding domain (RBD), the principal binding domain of the S protein located on the S1 subunit of SARS$\mathrm{CoV}-2$ virus. EGCG can be used as a potential prophylactic due to its ability to dock to various active sites of SARSCoV-2 virus. The authors highlighted the needing of additional studies on the specificity, safety, and efficacy of these polyphenols, to confirm their use not only as a dietary 
Table I A Summary of Pre-Clinical Studies on the Antiviral Activity of EGCG Against SARS-Cov-2

\begin{tabular}{|c|c|c|}
\hline Substance & Effect & Reference \\
\hline EGCG, TF3, TFs & $\begin{array}{l}\text { TF3 and EGCG by } \\
\text { interacting with the } \\
\text { receptors present in } \\
\text { SARS-CoV-2 virus, thus } \\
\text { inhibiting its replication. } \\
\text { TFs bind to Spike RBD. }\end{array}$ & [58] \\
\hline EGCG, GTE & $\begin{array}{l}\text { EGCG and GTE are able } \\
\text { to control the } \\
\text { inflammation damage } \\
\text { occurring in SARS-CoV-2 } \\
\text { infection by acting on } \\
\text { STAT, NF-KB, Nrf2 } \\
\text { signaling pathways. }\end{array}$ & [59] \\
\hline $\begin{array}{l}\text { EGCG, TQ, VITAMIN } \\
\text { D3 }\end{array}$ & $\begin{array}{l}\text { The combination of } \\
\text { EGCG, TQ AND } \\
\text { VITAMIN D3 activates } \\
\text { Nrf2-dependent genes } \\
\text { thus preventing the cells } \\
\text { against SARS-CoV-2 } \\
\text { infection. }\end{array}$ & {$[60]$} \\
\hline $\begin{array}{l}\text { EGCG, TFI, TF2a, TF2b, } \\
\text { hesperidin, } \\
\text { quercetagetin, and } \\
\text { myricetin }\end{array}$ & $\begin{array}{l}\text { EGCG, TFI, TF2a, TF2b, } \\
\text { TF3 bind stably to the } \\
\text { active site of RdRp. }\end{array}$ & {$[61]$} \\
\hline $\begin{array}{l}\text { SA, L-PGA, N-NPTA, } \\
\text { ACPS, EGCG, KDH and } \\
\text { SeM }\end{array}$ & $\begin{array}{l}\text { ACPS and KDH are } \\
\text { powerful species in the } \\
\text { treatment of SARS-CoV-2 } \\
\text { infection. }\end{array}$ & [62] \\
\hline $\begin{array}{l}\text { EGCG and TFs in } \\
\text { HEK } 2937\end{array}$ & $\begin{array}{l}\text { EGCG and TF inhibited } \\
\text { activity against the SARS- } \\
\text { CoV-2 3CL-protease, in } \\
\text { dose dependent manner } \\
\text { e without citotoxity for } \\
\text { treated cells. }\end{array}$ & [63] \\
\hline $\begin{array}{l}\text { EGCG, withaferin } A \text {, } \\
\text { dolutegravir and } \\
\text { artesunate }\end{array}$ & $\begin{array}{l}\text { EGCG, withaferin A, } \\
\text { dolutegravir and } \\
\text { artesunate could be } \\
\text { considered potential drugs } \\
\text { for SARS-CoV-2 infection. }\end{array}$ & [64] \\
\hline EGCG and TF3 & $\begin{array}{l}\text { EGCG and TF3 possess } \\
\text { broad-spectrum antiviral } \\
\text { activity in treatment of } \\
\text { SARS-CoV-2 infection. }\end{array}$ & [65] \\
\hline Flavan-3-ols and PAs & $\begin{array}{l}\text { CAG, ECG, GCG, and } \\
\text { EGCG inhibited the Mpro } \\
\text { activity of SARS-CoV- } 2 \text {. }\end{array}$ & [66] \\
\hline
\end{tabular}

(Continued)
Table I (Continued).

\begin{tabular}{|l|l|c|}
\hline Substance & \multicolumn{1}{|c|}{ Effect } & Reference \\
\hline $\begin{array}{l}\text { Trans-resveratrol, EGCG } \\
\text { and BX795 }\end{array}$ & $\begin{array}{l}\text { Trans-resveratrol, EGCG } \\
\text { and BX795 show multiple } \\
\text { antiviral effects against } \\
\text { SARS-CoV-2. }\end{array}$ & {$[67]$} \\
\hline PGG, EGCG & $\begin{array}{l}\text { PGG, EGCG inhibited the } \\
\text { viral protease activity of } \\
\text { SARS-CoV-2 3CLpro }\end{array}$ & {$[68]$} \\
\hline EGCG, active & $\begin{array}{l}\text { EGCG inhibits the } \\
\text { ingredients of TCM }\end{array}$ & $\begin{array}{l}\text { CCLPro activity of SARS- } \\
\text { CoV-2. }\end{array}$ \\
\hline EGCG & $\begin{array}{l}\text { EGCG inhibits HCoV- } \\
\text { OC43 and HCoV-229E } \\
\text { replication. }\end{array}$ & {$[70]$} \\
\hline EGCG, EGC & $\begin{array}{l}\text { EGCG and EGC inhibited } \\
\text { PLPro }\end{array}$ & {$[71]$} \\
\hline EGCG & $\begin{array}{l}\text { EGCG arrested the entry } \\
\text { of SARS-CoV-2, MERS and } \\
\text { SARS-CoV pseudotyped } \\
\text { lentiviral vectors and } \\
\text { restrained virus infections. } \\
\text { An inhibition of the SARS- } \\
\text { CoV-2 spike-receptor } \\
\text { interaction was also } \\
\text { detected. }\end{array}$ & {$[72]$} \\
\hline
\end{tabular}

Abbreviations: EGCG, epigallocatechin-3-gallate; TF3, theaflavin-3,3'-digallate; TFs, theaflavins; RBD, receptor-binding domain; STAT, signal transducer and activator of transcription; NF-kb, nuclear factor kappa-light-chain-enhancer of activated B cells; Nrf2, nuclear factor erythroid-derived 2-related factor 2; TQ, thymoquinone; RdRp, RNA-dependent RNA polymerase; SA, succinic acid; L-PGA, L-pyroglutamic acid; N-NPTA, N-phenyl-thioacetamide; ACPS, 2-amino-5-chloropyridine hydrogen succinate; $\mathrm{KDH}$, 2-oxoglutarate dehydrogenase El component, putative; SeM, selenomethionine; PAs, proanthocyanidins; $M^{\text {pro, }}$, main protease; CAG, catechin-3-O-gallate; ECG, (-)-epicatechin-3-O-gallate; PA2, procyanidin A2; PB2, procyanidin B2; PGG, I,2,3,4,6-pentagalloylglucose; 3CLpro, chymotrypsin-like protease; TCM, traditional medicine; HCoV-OC43, beta coronavirus; HCoV-229E, alpha coronavirus; PLPro, papain-like protease protein.

supplement, but also as therapeutic agents for COVID-19 infections. Menegazzi et al, ${ }^{59}$ speculated that EGCG and others catechins (ie, GTE) supplementation could be effective in controlling the inflammation damages occurring in SARS-CoV-2 infection, through complex molecular mechanisms involving different interacting transcriptor factors (ie signal transducer and activator of transcription, STAT; nuclear factor kappa-light-chain-enhancer of activated B cells, NF-кB; NF-E2-related factor 2; Nuclear Factor Erythroid-Derived 2-Related Factor 2, Nrf2). Similarly, Mendonca et al, ${ }^{60}$ suggested that the combination 


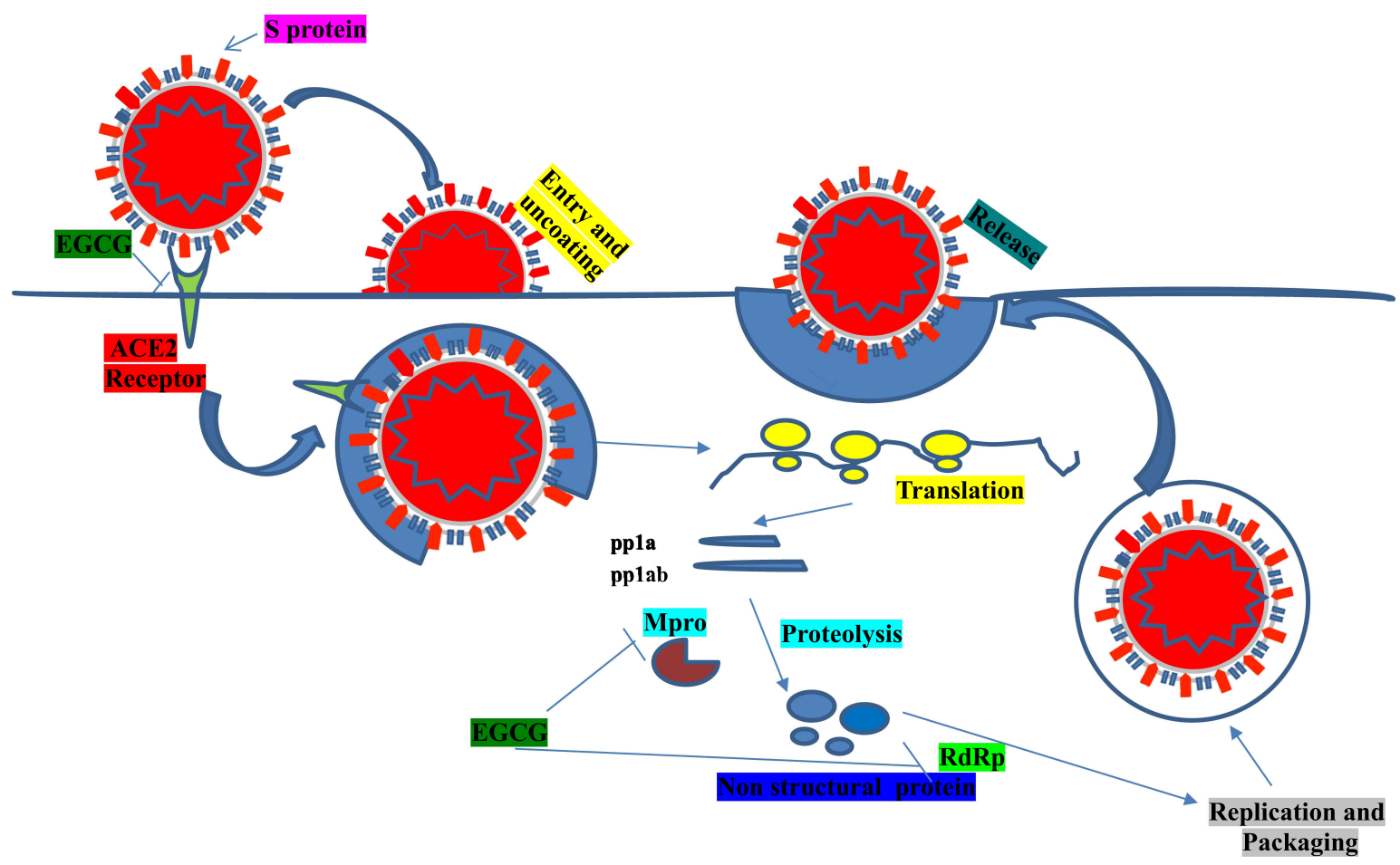

Figure I The inhibitory effects of EGCG on SARS-CoV-2 life cycle. The figure represents the inhibitory effects of EGCG on SARS-CoV-2 cycle. Basically, the inhibition effects of EGCG on SARS-CoV-2 replication occurs through its actions on the ACE2 receptor, the main protease (Mpro, a 3C-like protease) and RNA-dependent RNA polymerase (RdRp).

Abbreviations: EGCG, epigallocatechin-3-gallate; ppla, nuclear protein phosphatase I $\alpha$; pplab, 2'-O-methyltransferase; Mpro, main protease; ACE2, angiotensinconverting enzyme 2; S-protein, spike protein; RdRp, RNA-dependent RNA polymerase.

of EGCG, thymoquinone (TQ), and vitamin D3 can activate Nrf2-dependent genes and preserve the cells against SARSCoV-2 infection. Singh et al, ${ }^{61}$ studied the binding of polyphenols (ie, EGCG, TF1, TF2a, TF2b, hesperidin, quercetagetin, and myricetin) with SARS-CoV-2 RdRp and thus tested their potential to treat COVID-19. The authors demonstrated that EGCG, TF1, TF2a, TF2b, TF3, can bind (in highly stable manner) to the active site of RdRp. These four natural polyphenols can act as potential inhibitors for the SARS-CoV-2 RdRp, although additional studies will be necessary to validate their efficacy against SARS$\mathrm{CoV}-2$ infection. An in-silico analysis conducted by Sagaama et al, ${ }^{62}$ revealed that the succinic acid (SA), L-pyroglutamic acid (L-PGA), N-phenyl-thioacetamide (N-NPTA), 2-amino-5-chloropyridine hydrogen succinate (ACPS), epigallocatechine Gallate (EGCG) or, 2-oxoglutarate dehydrogenase E1 component putative $(\mathrm{KDH})$ and, selenomethionine (SeM) compounds could represented potential antiviral candidates for treatment of COVID-19 based on B3LYP/6-311++G** calculations and molecular docking. Data emerged from this study suggest that the compounds ACPS and $\mathrm{KDH}$ are powerful species in the treatment of SARS-CoV-2 infections. A different study conducted by Jang et al, ${ }^{63}$ demonstrated that EGCG and theaflavins, inhibited activity against the SARS-CoV-2 3CL-protease, in HEK293T cells, in a dose-dependent manner and without signs of cytotoxicity for both compounds at any dose used. Sharma et al, ${ }^{64}$ performed an in-silico drug repurposing followed by molecular dynamics (MD) simulation and MM-GBSA calculation for targeting SARS-CoV-2 main protease $\left(\mathrm{M}^{\mathrm{pro}}\right)$. $\mathrm{M}^{\text {pro }}$ was screened for already known FDA approved drugs and some natural compounds, including EGCG. Specifically, the authors proposed that EGCG, withaferin A, dolutegravir and artesunate could be considered potential drugs for COVID-19. A molecular docking studies was also conducted by Mhatre et al, ${ }^{65}$ to study the exact interaction of EGCG and TF3 with the putative binding sites of SARS-CoV-2. The in-silico results emerged from this study should promote the evaluation of the broadspectrum antiviral activity of the tea polyphenols in the treatment of COVID-19. Similarly, Zhu et al ${ }^{66}$ performed in vitro studies by using of the $\mathrm{M}^{\text {pro }}$ of SARS-Cov- 2 for docking simulation to screen flavan-3-ols and proanthocyanidins (Pas), to identify potential candidates for counteracting SARS-Cov-2 infection. Data emerged from docking simulation and in vitro assay, indicated that (-)-catechin 
-3-O-gallate (CAG), (-)-epicatechin-3-O-gallate (ECG), (-)-gallocatechin-3-O-gallate GCG), EGCG, procyanidin A2 (PA2) and B2 (PB2) are able to inhibit the $\mathrm{M}^{\text {pro }}$ activity of SARS-Cov-2, thus can be used to interfere with SARSCov-2 infection. Wang et al, ${ }^{67}$ conducted in-depth and comprehensive bioinformatics analysis for the screening of therapeutic drugs and their related pathways in COVID-19 disease. Results indicated that transresveratrol, EGCG and BX795 possess multiple anti-viral effects. It is of note that coronaviruses encode for polyproteins that are cleaved by $3 \mathrm{CL}$ protease for maturation. Thus, 3CL protease could be considered the main target of antivirals against coronaviruses. Based on this concept, Chiou et $\mathrm{al},{ }^{68}$ conducted an in vitro study on the inhibitory effects of 1,2,3,4,6-pentagalloylglucose (PGG) and EGCG against the SARS-CoV-2- 3-chymotrypsin-like protease (3CLpro) protease. Data revealed that PGG and EGCG inhibited of viral protease activity of SARS-CoV-2 3CLpro, thus suggesting their potential application in the treatment of SARSCoV-2 infection. Later on, in a fascinating study Du et al, ${ }^{69}$ screened and identified, by using multiple strategies (ie molecular docking, surface plasmon resonance, fluorescence resonance energy transfer (FRET)-based inhibition assay) different active ingredients of Traditional Chinese Medicine (TCM) with inhibitory effects against SARS-CoV -2 3CLpro, including EGCG. Results demonstrate that EGCG showed a higher affinity with SARS-CoV-2 3CLpro thus suggesting its potential in the treatment of COVID-19 disease. A fascinating in vitro study performed by Jang et al, ${ }^{70}$ demonstrated that EGCG can inhibit coronavirus replication. Specifically, the authors used low pathogenic human coronavirus $\mathrm{HCoV}-\mathrm{OC} 43$ (beta coronavirus) and $\mathrm{HCoV}-229 \mathrm{E}$ (alpha coronavirus), as a coronavirus model system to dissect the effect of EGCG on coronavirus processing. Results demonstrated that EGCG treatment decreases viral RNA and viral protein production in the media suggesting that EGCG inhibits coronavirus replication. By using the molecular docking approach, Chourasia et $\mathrm{al}^{71}$ demonstrated that the catechins (mainly EGCG and ECG) inhibited papain-like protease protein (PLPro). Specifically, catechin bind to the S1 ubiquitin-binding site of PLPro, which restrain its protease function and abolish SARS-CoV-2 inhibitory function on ubiquitin proteasome system and interferon stimulated gene system. Considering EGGC's antiviral and antiinflammatory properties, the authors concluded that these natural compounds could be considered as a putative therapeutic agent for SARS-CoV-2 infection. Finally, a recent research conducted by Henss et al, ${ }^{72}$ examined the antiviral activity of EGCG against SARS-CoV-2. EGCG arrested the entry of SARS-CoV-2, MERS and SARS-CoV pseudo typed lentiviral vectors and restrained virus infections in vitro. Moreover, an inhibition of the SARS-CoV-2 spike-receptor interaction was also detected. Altogether these finding highlighted the potential use of EGCG as an alternative therapeutic choice for the treatment of SARSCoV-2 infection.

\section{Conclusions and Future Perspectives}

Here, we summarized recent findings on the potential role of EGCG in the treatment of SARS-CoV-2 infection. Accumulated pieces of evidence reported that EGCG has antiviral properties against different viruses, including SARS-Cov-2. ${ }^{22}$ Specifically, it has been proved that EGCG inhibits the enzymatic activity of the coronavirus 3CL protease, thus interfering with its replication. Moreover, EGCG can regulate specific target as the viral $S$ protein and RdRp. EGCG is also capable of inhibiting the replication of coronaviruses in cell cultures. Results from molecular docking analyses demonstrated that EGCG prevents SARS-CoV-2 entry into the target cell through inhibition of RBD in viral membrane identifying with ACE2. Finally, EGCG can interfere with the viral start replication by suppressing Mpro activity, although all these effects should be confirmed in vivo. A set of experiments evaluated the in vivo distribution of EGCG in human bodies ${ }^{74-79}$ and data showed that the values of EGCG concentration in the colon and intestine were higher than most of the concentrations necessary to promote $3 \mathrm{CL}$ protease required to effectively $3 \mathrm{CL}$ protease inhibition. More pre-clinical studies, clinical trials and epidemiological analysis will be extremely needed to validate EGCG anti-COVID-19 applications. EGCG and its stable lipophilic derivatives could also be potential prophylactic as well as therapeutic agents looking at their properties to dock at various active sites of SARS-CoV -2 . Results from these studies will shed light on the role of the EGCG and the underlying molecular mechanisms for the treatment of SARS-CoV-2 infection. However, based on the current results published in the literature, it is not possible to say at all that EGCG can be considered as an election therapeutic drug for Covid-19. Due to the absence of specificity, EGCG could bind to other proteins present in the human body, thus provoking side-effects. EGGC 
may not be used in the treatment of COVID-19, but as a nutraceutical or dietary supplement, especially in the earlier stages of clinical manifestations of COVID-19. After extensive studies on EGGC and other similar polyphenols regarding their specificity, activity, bioavailability and safety, there can be considerations on their use in the treatment of viral infections including COVID-19.

\section{Acknowledgments}

We are grateful to Dr. Alessandra Trocino and Mrs. Cristina Romano from the National Cancer Institute of Naples for providing excellent bibliographic service and assistance. Sabrina Bimonte and Cira Antonietta Forte are co-first authors of this study. Marco Cascella and Arturo Cuomo are co-last authors of this study.

\section{Author Contributions}

All authors contributed to data analysis, drafting or revising the article, have agreed on the journal to which the article will be submitted, gave final approval for the version to be published, and agree to be accountable for all aspects of the work.

\section{Disclosure}

The authors report no conflicts of interest in this work.

\section{References}

1. Bimonte S, Crispo A, Amore A, Celentano E, Cuomo A, Cascella M. Potential antiviral drugs for SARS-Cov-2 treatment: preclinical findings and ongoing clinical research. In vivo. 2020;34(3 Suppl):1597-1602. doi:10.21873/invivo.11949

2. Wu F, Zhao S, Yu B, et al. A new coronavirus associated with human respiratory disease in China. Nature. 2020;579(7798):265-269. doi:10.1038/s41586-020-2008-3

3. Wiersinga WJ, Rhodes A, Cheng AC, Peacock SJ, Prescott HC. Pathophysiology, transmission, diagnosis, and treatment of coronavirus disease 2019 (COVID-19): a review. JAMA. 2020;324 (8):782-793. doi:10.1001/jama.2020.12839

4. Petersen E, Koopmans M, Go U, et al. Comparing SARS-CoV-2 with SARS-CoV and influenza pandemics. Lancet Infect Dis. 2020;20(9): e238-e244. doi:10.1016/S1473-3099(20)30484-9

5. Nagy A, Alhatlani B. An overview of current COVID-19 vaccine platforms. Comput Struct Biotechnol J. 2021;19:2508-2517. doi:10.1016/j.csbj.2021.04.061

6. Vitiello A, Ferrara F, Porta R. Remdesivir and COVID-19 infection, therapeutic benefits or unnecessary risks? Ir J Med Sci. 2021;1-2. doi:10.1007/s11845-020-02482-2

7. Baden LR, El Sahly HM, Essink B, et al.; COVE Study Group. Efficacy and safety of the mRNA-1273 SARS-CoV-2 vaccine. N Engl J Med. 2021;384(5):403-416. doi:10.1056/NEJMoa2035389

8. Xia X. Domains and functions of spike protein in Sars-Cov-2 in the context of vaccine design. Viruses. 2021;13(1):109. doi:10.3390/ v13010109
9. Bjørnstad-Tuveng TH, Rudjord A, Anker P. Fatal cerebral haemorrhage after COVID-19 vaccine. Tidsskr nor Laegeforen. 2021;141. English, Norwegian. doi:10.4045/tidsskr.21.0312

10. Maas DPMSM, Kramers C, Smit HJCA, Middeldorp S, Helsloot I. Prikpauze AstraZeneca proportioneel? [Temporary suspension of AstraZeneca's vaccine; a reconstruction]. Ned Tijdschr Geneeskd. 2021;165:D6065. Dutch.

11. CDC Emerging Sars-Cov-2 Variants. Available from: https://www. cdc.gov/coronavirus/2019-ncov/more/science-and-research/scientificbrief-emerging-variants.html\#. Accessed January 28, 2021.

12. Bimonte S, Cascella M. The potential roles of epigallocatechin-3-gallate in the treatment of ovarian cancer: current state of knowledge. Drug Des Devel Ther. 2020;14:4245-4250. doi:10.2147/DDDT.S253092

13. Bimonte S, Cascella M, Barbieri A, Arra C, Cuomo A. Current shreds of evidence on the anticancer role of EGCG in triple negative breast cancer: an update of the current state of knowledge. Infect Agent Cancer. 2020;15:2. doi:10.1186/s13027-020-0270-5

14. Bimonte S, Cascella M, Barbieri A, Arra C, Cuomo A. Shining a light on the effects of the combination of (-)-epigallocatechin -3-gallate and tapentadol on the growth of human triple-negative breast cancer cells. In Vivo. 2019;33(5):1463-1468. doi:10.21873/ invivo. 11625

15. Bimonte S, Albino V, Piccirillo M, et al. Epigallocatechin-3-gallate in the prevention and treatment of hepatocellular carcinoma: experimental findings and translational perspectives. Drug Des Devel Ther. 2019;13:611-621. doi:10.2147/DDDT.S180079

16. Cascella M, Bimonte S, Muzio MR, Schiavone V, Cuomo A. The efficacy of Epigallocatechin-3-gallate (green tea) in the treatment of Alzheimer's disease: an overview of pre-clinical studies and translational perspectives in clinical practice. Infect Agent Cancer. 2017;12:36. doi:10.1186/s13027-017-0145-6

17. Bimonte $S$, Cascella $M$, Leongito $M$, et al. An overview of pre-clinical studies on the effects of (-)-epigallocatechin-3-gallate, a catechin found in green tea, in treatment of pancreatic cancer. Recenti Prog Med. 2017;108(6):282-287. doi:10.1701/2715.27715

18. Bimonte S, Leongito M, Barbieri A, et al. Inhibitory effect of (-)epigallocatechin-3-gallate and bleomycin on human pancreatic cancer MiaPaca-2 cell growth. Infect Agent Cancer. 2015;10:22. doi:10.1186/s13027-015-0016-y

19. Nagle DG, Ferreira D, Zhou YD. Epigallocatechin-3-gallate (EGCG): chemical and biomedical perspectives. Phytochemistry. 2006;67 (17):1849-1855. doi:10.1016/j.phytochem.2006.06.020

20. Xu J, Xu Z, Zheng W. A review of the antiviral role of green tea catechins. Molecules. 2017;22(8):1337. doi:10.3390/molecules22 081337

21. Steinmann J, Buer J, Pietschmann T, Steinmann E. Anti-infective properties of epigallocatechin-3-gallate (EGCG), a component of green tea. Br J Pharmacol. 2013;168(5):1059-1073. doi:10.1111/ bph. 12009

22. Wang YQ, Li QS, Zheng XQ, Lu JL, Liang YR. Antiviral effects of green tea EGCG and its potential application against COVID-19. Molecules. 2021;26(13):3962. doi:10.3390/molecules26133962

23. Xu J, Gu W, Li C, et al. Epigallocatechin gallate inhibits hepatitis B virus via farnesoid X receptor alpha. J Nat Med. 2016;70 (3):584-591. doi:10.1007/s11418-016-0980-6

24. Zhong L, Hu J, Shu W, Gao B, Xiong S. Epigallocatechin-3-gallate opposes HBV-induced incomplete autophagy by enhancing lysosomal acidification, which is unfavorable for HBV replication. Cell Death Dis. 2015;6(5):e1770. doi:10.1038/cddis.2015.136

25. Pang JY, Zhao KJ, Wang JB, Ma ZJ, Xiao XH. Green tea polyphenol, epigallocatechin-3-gallate, possesses the antiviral activity necessary to fight against the hepatitis B virus replication in vitro. J Zhejiang Univ Sci B. 2014;15(6):533-539. doi:10.1631/jzus. B1300307 
26. Chen M, Sällberg M, Hughes J, et al. Immune tolerance split between hepatitis B virus precore and core proteins. J Virol. 2005;79 (5):3016-3027. doi:10.1128/JVI.79.5.3016-3027.2005

27. He W, Li LX, Liao QJ, Liu CL, Chen XL. Epigallocatechin gallate inhibits HBV DNA synthesis in a viral replication - inducible cell line. World J Gastroenterol. 2011;17(11):1507-1514. doi:10.3748/ wjg.v17.i11.1507

28. Haberichter J, Roberts S, Abbasi I, Dedthanou P, Pradhan P, Nguyen ML. The telomerase inhibitor MST-312 interferes with multiple steps in the herpes simplex virus life cycle. $J$ Virol. 2015;89 (19):9804-9816. doi:10.1128/JVI.01006-15

29. Isaacs CE, Wen GY, Xu W, et al. Epigallocatechin gallate inactivates clinical isolates of herpes simplex virus. Antimicrob Agents Chemother. 2008;52(3):962-970. doi:10.1128/AAC.00825-07

30. Gosslau A, En Jao DL, Huang MT, et al. Effects of the black tea polyphenol theaflavin-2 on apoptotic and inflammatory pathways in vitro and in vivo. Mol Nutr Food Res. 2011;55(2):198-208. doi:10.1002/mnfr.201000165

31. Pradhan P, Nguyen ML. Herpes simplex virus virucidal activity of MST-312 and epigallocatechin gallate. Virus Res. 2018;249:93-98. doi:10.1016/j.virusres.2018.03.015

32. Kutok JL, Wang F. Spectrum of Epstein-Barr virus-associated diseases. Annu Rev Pathol. 2006;1:375-404. doi:10.1146/annurev. pathol.1.110304.100209

33. Lo YM. Quantitative analysis of Epstein-Barr virus DNA in plasma and serum: applications to tumor detection and monitoring. Ann N Y Acad Sci. 2001;945:68-72. doi:10.1111/j.1749-6632.2001. tb03865.x

34. Chang LK, Wei TT, Chiu YF, et al. Inhibition of Epstein-Barr virus lytic cycle by (-)-epigallocatechin gallate. Biochem Biophys Res Commun. 2003;301(4):1062-1068. doi:10.1016/s0006-291x(03) 00067-6

35. Liu S, Li H, Chen L, et al. (-)-Epigallocatechin-3-gallate inhibition of Epstein-Barr virus spontaneous lytic infection involves ERK1/2 and PI3-K/Akt signaling in EBV-positive cells. Carcinogenesis. 2013;34 (3):627-637. doi:10.1093/carcin/bgs364

36. Hamza A, Zhan CG. How can (-)-epigallocatechin gallate from green tea prevent HIV-1 infection? Mechanistic insights from computational modeling and the implication for rational design of anti-HIV1 entry inhibitors. J Phys Chem B. 2006;110(6):2910-2917. doi:10.1021/jp0550762

37. Zhang HS, Wu TC, Sang WW, Ruan Z. EGCG inhibits Tat-induced LTR transactivation: role of Nrf2, AKT, AMPK signaling pathway. Life Sci. 2012;90(19-20):747-754. doi:10.1016/j.lfs.2012.03.013

38. Williamson MP, McCormick TG, Nance CL, Shearer WT. Epigallocatechin gallate, the main polyphenol in green tea, binds to the T-cell receptor, CD4: potential for HIV-1 therapy. J Allergy Clin Immunol. 2006;118(6):1369-1374. doi:10.1016/j.jaci.2006.08.016

39. Castellano LM, Hammond RM, Holmes VM, Weissman D, Shorter J. Epigallocatechin-3-gallate rapidly remodels PAP85-120, SEM1(45107), and SEM2(49-107) seminal amyloid fibrils. Biol Open. 2015;4 (9):1206-1212. doi:10.1242/bio.010215

40. Duan JM, Qiu JY, Tan SY, Liu SW, Li L. [Semen-derived enhancer of viral infection-a key factor in sexual transmission of HIV]. Bing Du Xие Bao. 2012;28(1):84-88. Chinese.

41. Hauber I, Hohenberg H, Holstermann B, Hunstein W, Hauber J. The main green tea polyphenol epigallocatechin-3-gallate counteracts semen-mediated enhancement of HIV infection. Proc Natl Acad Sci US A. 2009;106(22):9033-9038. doi:10.1073/pnas.0811827106

42. Li S, Hattori T, Kodama EN. Epigallocatechin gallate inhibits the HIV reverse transcription step. Antivir Chem Chemother. 2011;21 (6):239-243. doi:10.3851/IMP1774

43. Liu S, Lu H, Zhao Q, et al. Theaflavin derivatives in black tea and catechin derivatives in green tea inhibit HIV-1 entry by targeting gp41. Biochim Biophys Acta. 2005;1723(1-3):270-281. doi:10.1016/j.bbagen.2005.02.012
44. Wang YF, Shao SH, Xu P, Yang XQ, Qian LS. Catechin-enriched green tea extract as a safe and effective agent for antimicrobial and anti-inflammatory treatment. Afr $J$ Pharm Pharmacol. 2011;5:1452-1461. doi:10.5897/AJPP11.164

45. Kuzuhara T, Iwai Y, Takahashi H, Hatakeyama D, Echigo N. Green tea catechins inhibit the endonuclease activity of influenza A virus RNA polymerase. PLoS Curr. 2009;1:RRN1052. doi:10.1371/currents.rrn1052

46. Kim M, Kim SY, Lee HW, et al. Inhibition of influenza virus internalization by (-)-epigallocatechin-3-gallate. Antiviral Res. 2013;100 (2):460-472. doi:10.1016/j.antiviral.2013.08.002

47. Ling JX, Wei F, Li N, et al. Amelioration of influenza virus-induced reactive oxygen species formation by epigallocatechin gallate derived from green tea. Acta Pharmacol Sin. 2012;33(12):1533-1541. doi:10.1038/aps.2012.80

48. Song JM, Lee KH, Seong BL. Antiviral effect of catechins in green tea on influenza virus. Antiviral Res. 2005;68(2):66-74. doi:10.1016/ j.antiviral.2005.06.010

49. He X, Gao B, Zhou L, Xiong S. Green tea polyphenol epigallocatechin-3-gallate-alleviated coxsackievirus B3-induced myocarditis through inhibiting viral replication but not through inhibiting inflammatory responses. J Cardiovasc Pharmacol. 2017;69 (1):41-47. doi:10.1097/FJC.0000000000000439

50. Ho HY, Cheng ML, Weng SF, Leu YL, Chiu DT. Antiviral effect of epigallocatechin gallate on enterovirus 71. J Agric Food Chem. 2009;57(14):6140-6147. doi:10.1021/jf901128u

51. Carneiro BM, Batista MN, Braga ACS, Nogueira ML, Rahal P. The green tea molecule EGCG inhibits Zika virus entry. Virology. 2016;496:215-218. doi:10.1016/j.virol.2016.06.012

52. Weber C, Sliva K, von Rhein C, Kümmerer BM, Schnierle BS. The green tea catechin, epigallocatechin gallate inhibits chikungunya virus infection. Antiviral Res. 2015;113:1-3. doi:10.1016/j. antiviral.2014.11.001

53. Lu JW, Hsieh PS, Lin CC, et al. Synergistic effects of combination treatment using EGCG and suramin against the chikungunya virus. Biochem Biophys Res Commun. 2017;491(3):595-602. doi:10.1016/j. bbrc.2017.07.157

54. Vazquez-Calvo Á, Jiménez de Oya N, Martín-Acebes MA, GarciaMoruno E, Saiz JC. Antiviral properties of the natural polyphenols delphinidin and epigallocatechin gallate against the flaviviruses West Nile virus, Zika virus, and Dengue virus. Front Microbiol. 2017;8:1314. doi:10.3389/fmicb.2017.01314

55. Su S, Wong G, Shi W, et al. Epidemiology, genetic recombination, and pathogenesis of coronaviruses. Trends Microbiol. 2016;24 (6):490-502. doi:10.1016/j.tim.2016.03.003

56. Zhou P, Yang XL, Wang XG, et al. A pneumonia outbreak associated with a new coronavirus of probable bat origin. Nature. 2020;579 (7798):270-273. doi:10.1038/s41586-020-2012-7

57. Weiss SR, Navas-Martin S. Coronavirus pathogenesis and the emerging pathogen severe acute respiratory syndrome coronavirus. Microbiol Mol Biol Rev. 2005;69(4):635-664. doi:10.1128/ MMBR.69.4.635-664.2005

58. Mhatre S, Srivastava T, Naik S, Patravale V. Antiviral activity of green tea and black tea polyphenols in prophylaxis and treatment of COVID-19: a review. Phytomedicine. 2021;85:153286. doi:10.1016/j. phymed.2020.153286

59. Menegazzi M, Campagnari R, Bertoldi M, Crupi R, Di Paola R, Cuzzocrea S. Protective effect of epigallocatechin-3-gallate (EGCG) in diseases with uncontrolled immune activation: could such a scenario be helpful to counteract COVID-19? Int J Mol Sci. 2020;21(14):5171. doi:10.3390/ijms21145171

60. Mendonca P, Soliman KFA. Flavonoids activation of the transcription factor Nrf2 as a hypothesis approach for the prevention and modulation of SARS-CoV-2 infection severity. Antioxidants. 2020;9(8):659. doi:10.3390/antiox9080659 
61. Singh S, Sk MF, Sonawane A, Kar P, Sadhukhan S. Plant-derived natural polyphenols as potential antiviral drugs against SARS-CoV-2 via RNA-dependent RNA polymerase (RdRp) inhibition: an in-silico analysis. J Biomol Struct Dyn. 2020;28:1-16. doi:10.1080/ 07391102.2020.1796810

62. Sagaama A, Brandan SA, Ben Issa T, Issaoui N. Searching potential antiviral candidates for the treatment of the 2019 novel coronavirus based on DFT calculations and molecular docking. Heliyon. 2020;6 (8):e04640. doi:10.1016/j.heliyon.2020.e04640

63. Jang M, Park YI, Cha YE, et al. Tea polyphenols EGCG and theaflavin inhibit the activity of SARS-CoV-2 3CL-protease in vitro. Evid Based Complement Alternat Med. 2020;2020:5630838. doi:10.1155/ 2020/5630838

64. Sharma S, Deep S. In-silico drug repurposing for targeting SARS-CoV-2 main protease (Mpro). $J$ Biomol Struct Dyn. 2020;12:1-8. doi:10.1080/07391102.2020.1844058

65. Mhatre S, Naik S, Patravale V. A molecular docking study of EGCG and theaflavin digallate with the druggable targets of SARS-CoV-2. Comput Biol Med. 2021;129:104137. doi:10.1016/j. compbiomed.2020.104137

66. Zhu Y, Xie DY. Docking characterization and in vitro inhibitory activity of flavan-3-ols and dimeric proanthocyanidins against the main protease activity of SARS-Cov-2. Front Plant Sci. 2020;11:601316. doi:10.3389/fpls.2020.601316

67. Wang T, Zhao M, Ye P, Wang Q, Zhao Y. Integrated bioinformatics analysis for the screening of associated pathways and therapeutic drugs in coronavirus disease 2019. Arch Med Res. 2021;52 (3):304-310. doi:10.1016/j.arcmed.2020.11.009

68. Chiou WC, Chen JC, Chen YT, et al. The inhibitory effects of PGG and EGCG against the SARS-CoV-2 3C-like protease. Biochem Biophys Res Commun. 2021. doi:10.1016/j.bbrc.2020.12.106

69. Du A, Zheng R, Disoma C, et al. Epigallocatechin-3-gallate, an active ingredient of Traditional Chinese Medicines, inhibits the 3CLpro activity of SARS-CoV-2. Int $J$ Biol Macromol. 2021;176:1-12. doi:10.1016/j.ijbiomac.2021.02.012
70. Jang M, Park R, Park YI, et al. EGCG, a green tea polyphenol, inhibits human coronavirus replication in vitro. Biochem Biophys Res Commun. 2021;547:23-28. doi:10.1016/j.bbrc.2021.02.016

71. Chourasia M, Koppula PR, Battu A, Ouseph MM, Singh AK. EGCG, a green tea catechin, as a potential therapeutic agent for symptomatic and asymptomatic SARS-CoV-2 infection. Molecules. 2021;26 (5):1200. doi:10.3390/molecules26051200

72. Henss L, Auste A, Schürmann C, et al. The green tea catechin epigallocatechin gallate inhibits SARS-CoV-2 infection. $J$ Gen Virol. 2021;102(4):001574. doi:10.1099/jgv.0.001574

73. Park J, Park R, Jang M, Park YI. Therapeutic potential of EGCG, a green tea polyphenol, for treatment of coronavirus diseases. Life. 2021;11(3):197. doi:10.3390/life11030197

74. Lambert JD, Lee $\mathrm{MJ}$, $\mathrm{Lu} \mathrm{H}$, et al. Epigallocatechin-3-gallate is absorbed but extensively glucuronidated following oral administration to mice. $J$ Nutr. 2003;133(12):4172-4177. doi:10.1093/jn/ 133.12.4172

75. Nakagawa K, Miyazawa T. Absorption and distribution of tea catechin, (-)-epigallocatechin-3-gallate, in the rat. J Nutr Sci Vitaminol. 1997;43(6):679-684. doi:10.3177/jnsv.43.679

76. Hollman PC, Tijburg LB, Yang CS. Bioavailability of flavonoids from tea. Crit Rev Food Sci Nutr. 1997;37(8):719-738. doi:10.1080/10408399709527799

77. Yang CS, Lee MJ, Chen L. Human salivary tea catechin levels and catechin esterase activities: implication in human cancer prevention studies. Cancer Epidemiol Biomarkers Prev. 1999;8(1):83-89.

78. Li Y, Ren B, Peng X, et al. Saliva is a non-negligible factor in the spread of COVID-19. Mol Oral Microbiol. 2020;35(4):141-145. doi:10.1111/omi.12289

79. Ohgitani E, Shin-Ya M, Ichitani M, et al. Rapid inactivation in vitro of SARS-CoV-2 in saliva by black tea and green tea. Pathogens. 2021;10(6):721. doi:10.3390/pathogens 10060721

\section{Publish your work in this journal}

Drug Design, Development and Therapy is an international, peerreviewed open-access journal that spans the spectrum of drug design and development through to clinical applications. Clinical outcomes, patient safety, and programs for the development and effective, safe, and sustained use of medicines are a feature of the journal, which has also been accepted for indexing on PubMed Central. The manuscript management system is completely online and includes a very quick and fair peer-review system, which is all easy to use. Visit http://www. dovepress.com/testimonials.php to read real quotes from published authors. 